\title{
The Improved Low Voltage Ride through Technology of the Directly-Drive Permanent Magnet Wind Turbines
}

\author{
Huiting Chen ${ }^{1}$, Shaojie Xin ${ }^{2}$, Enxing Yang ${ }^{3}$ \\ ${ }^{1}$ School of Electrical Engineering, Shanghai Dianji University, Shanghai, China. \\ 2 School of Mechanical Engineering, Shanghai Dianji University, Shanghai, China. \\ ${ }^{3}$ Shanghai Electric Power Transmission \& Distribution on Group Technology Center, Shanghai, China. \\ * Corresponding author. Tel.: 86 18964586645; email: 2304077519@qq.com \\ Manuscript submitted July 11, 2017; accepted September 19, 2017. \\ doi: 10.17706/ijcee.2018.10.1.12-22
}

\begin{abstract}
In order to further maintain the power balance on both sides of the DC capacitor and make the direct drive permanent magnet wind turbine generators(DPMSG) carry out low voltage ride through safely, the paper proposed a improved low voltage ride through(LVRT) strategy, harmonious flux-weakening control(HFWC), based on the magnetic field characteristics of permanent magnet synchronous motor when the grid voltage dropped. When the grid voltage dropped, in order to reduce the output active power of the generator, it changes the maximum power curve and reduces electromagnetic torque on the one hand, on the other hand, adding a negative current for $\mathrm{d}$-axis in the machine side to achieve weak magnetic control and the value of compensation current increased with the increase of the DC bus voltage. So the current in $d$ axis and q axis worked with each other and make the back EMF of generator decreased ,and the output active power of generator changed with the output active power of the grid. Finally, the simulation model of PMSG was built in Matlab/Simulink, and the control strategy was simulated and verified. Experimental results show that the flux-weakening control method is effective, and the harmonious flux-weakening control strategy(HFWC) made full use of the mechanical and electrical inertia energy storage, and reduced the use frequency of the unloading resistance, thus the wind turbines realized LVRT safely when the grid voltage dropped.
\end{abstract}

Key words: Directly-drive permanent magnet wind turbines, low voltage ride-through, weak magnetic control, simulink.

\section{Introduction}

With the rapid development of wind power technology and the growing scale of wind farm, the influence of wind power system on power system become more and more big. The direct drive permanent magnet wind turbine (Direct Drive Permanent Magnet Synchronous Generator For Wind Power, DPMSG) which has some advantages,such as its simple structure, stable operation, convenient maintenance, has become a research in recent type of power grid system. According to the existing rules requirement of interconnection, in these references [1]-[4], wind motor group should have the ability of some low voltage crossing. Namely, when the grid voltage drop occurs, fans were not allowed to take off the grid in the voltage drop range, and the control system should supply reactive power for power supply. Only when the grid has serious failure, fans could be allowed off network. According to the literature [5], [6], the method that this installation of Crowbar circuit in DC the consumption side can consume the unbalanced power when the 
grid voltage drops, was only suitable for the voltage drop or fall short of mild, but also will be faced with the problem of heat dissipation energy resistance. In the references [7]-[11], there were the electrical energy storage and pitch control when the grid voltage drops. But the power adjusting speed was low, the output power can not follow the changes of the machine side grid side power output and change. The storage units were used to store DC unbalanced power of the drop grid voltage for improving the operation cost of wind power system in the literature [12], [13].

\section{Wind Turbine Operating Characteristics Analysis}

In direct drive permanent magnet wind power system, the wind turbine which converts wind energy into mechanical energy plays an important role in energy conversion. In the establishment of a set of mathematical models, a mathematical model of wind turbine was more complex, involving the wind wheel geometry, complex calculation problem of long, wind speed signal model. We should focus on the basic theory of aerodynamics of blade based to achieve the accurate mathematical model of wind turbine . For simplicity and without losing the authenticity, we usually design a simple model to describe the wind turbine which can be obtained by references [14], [15]. Wind energy capture of wind turbine:

$$
P=\frac{1}{2} \rho \pi R^{2} v^{3} C_{p}(\lambda, \beta)
$$

where $\rho$ was air density, $R$ was wind wheel radius, v was wind speed, $C_{p}$ was wind energy utilization coefficient, $\lambda$ was the ratio of wind turbine tip speed and $\beta$ was pitch angle.

Therefore, the output torque of the wind turbine was:

$$
T_{m}=\frac{P}{\omega_{m}}=\frac{1}{2 \lambda} \rho \pi R^{3} v^{2} C_{p}(\lambda, \beta)
$$

\section{Mathematical Model of Direct Drive Permanent Magnet Wind Turbine}

\subsection{Mathematical Model of Permanent Magnet Synchronous Generator}

In direct drive wind power generation system, the wind turbine was coupling of permanent magnet synchronous motor directly. Permanent magnet synchronous motor, without electrical excitation winding, has some advantages, such as, a permanent magnet rotor magnetic field, has the advantages of high efficiency, small volume, convenient maintenance and so on. When the permanent magnet synchronous motor rotates, the relative position of stator and rotor changes with time. It was difficult to accurately analyze the coupling relationship of the parameters. Therefore, It was assumed that the permanent magnet synchronous motor (PMSM) has a sinusoidal distribution in the air gap when we established the mathematical model of permanent magnet synchronous motor. The stator flux linkage equation of PMSM dq coordinate system can be obtained by coordinate transformation:

$$
\left[\begin{array}{l}
\psi_{s d} \\
\psi_{s q} \\
\psi_{s 0}
\end{array}\right]=\left[\begin{array}{lll}
L_{d} & 0 & 0 \\
0 & L_{q} & 0 \\
0 & 0 & L_{0}
\end{array}\right]\left[\begin{array}{l}
i_{s d} \\
i_{s q} \\
i_{s 0}
\end{array}\right]+\left[\begin{array}{l}
\Psi_{f} \\
0 \\
0
\end{array}\right]
$$

The stator voltage equation of the permanent magnet synchronous generator in the dq rotating coordinate system was: 


$$
\left\{\begin{array}{l}
U_{s d}=-R_{s} i_{s d}-\omega_{e} \psi_{s q}+\frac{d \psi_{s d}}{d t} \\
U_{s q}=-R_{s} i_{s q}+\omega_{e} \psi_{s d}+\frac{d \psi_{s d}}{d t}
\end{array}\right.
$$

where $U_{s d}$ and $U_{s q}$ were stator voltages of permanent magnet synchronous generator in dq axis components. $i_{s d}$ and $i_{s q}$ were permanent magnet synchronous generator stator current in dq axis components. $\psi_{s d}$ and $\psi_{s q}$ were the stator flux of the generator in the $\mathrm{dq}$ axis components. $\omega_{e}$ was Electric angular velocity of permanent magnet synchronous motor.

The upper (3) into the upper (4) available (5):

$$
\left\{\begin{array}{l}
U_{s d}=-R_{s} i_{s d}+\omega_{e} L_{s q} i_{s q}-L_{s d} \frac{d i_{s d}}{d t} \\
U_{s q}=-R_{s} i_{s q}-\omega_{e} L_{s d} i_{s d}-L_{s q} \frac{d i_{s q}}{d t}+\omega_{e} \psi_{f}
\end{array}\right.
$$

where $\psi_{f}$ was permanent magnet flux linkage. And the equivalent circuit of the permanent magnet synchronous motor can be drawn on the dq axis. As shown below, in the rotating coordinate system, we can see that the mathematical model of permanent magnet synchronous motor (PMSM) has been greatly simplified, so it brings great convenience to us.

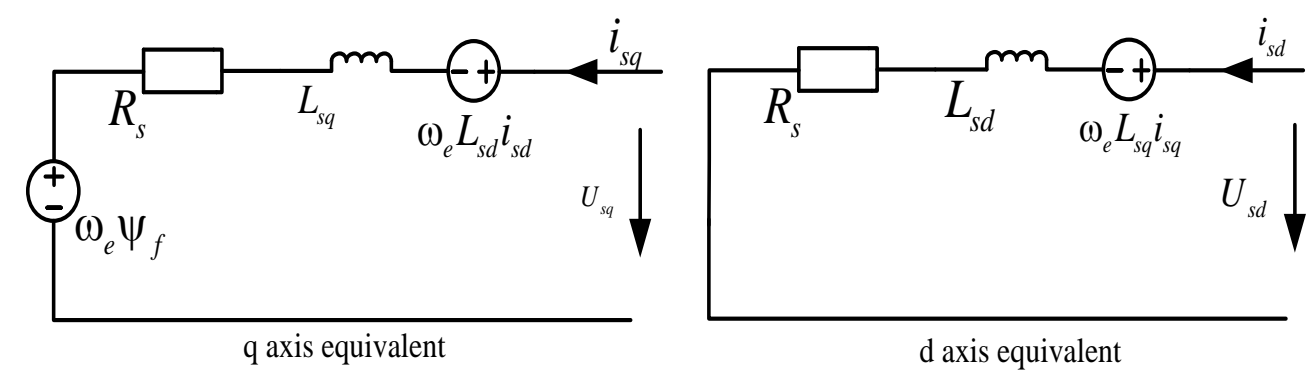

Fig. 1. The dq axis equivalent circuit of permanent magnet synchronous motor.

According to the references, the electromagnetic torque equation of PMSM in rotating coordinate system was obtained:

$$
T_{e}=\frac{3}{2} N_{p}\left[\psi_{f} i_{s q}+\left(i_{s d}-i_{s q}\right) i_{s d} i_{s q}\right]
$$

where $N_{p}$ was motor pole pair. Instantaneous active power $P_{s}$ output in dq rotating coordinate system of generator stator and the reactive power $Q_{s}$ can be calculated by the following formula:

$$
\left\{\begin{array}{l}
P_{s}=u_{s d} i_{s d}+u_{s q} i_{s q} \\
Q_{s}=u_{s q} i_{s d}-u_{s d} i_{s q}
\end{array}\right.
$$

\subsection{Mathematical Model of Grid Side Inverter}

In the establishment of the mathematical model of the grid side inverter, the grid side three-phase PWM 
converter was regarded as an ideal power electronic component:

1 The power supply voltage of the grid was set as a three-phase symmetrical sine wave;

2 The full power converter was designed as the ideal power electronics;

3 It was supposed that the inductance of the filter was linear and unsaturated;

The grid side inverter was connected to the power grid through the filter. Under the above assumptions, the mathematical equation of the static three-phase coordinate system was:

$$
L \frac{d}{d t}\left[\begin{array}{l}
i_{g a} \\
i_{g b} \\
i_{g c}
\end{array}\right]+R\left[\begin{array}{l}
i_{g a} \\
i_{g b} \\
i_{g c}
\end{array}\right]=\left[\begin{array}{l}
u_{g a} \\
u_{g b} \\
u_{g c}
\end{array}\right]-\left[\begin{array}{l}
u_{c a} \\
u_{c b} \\
u_{c c}
\end{array}\right]
$$

where $\mathrm{L}$ was the inductance of the net side filter, $R$ was the line impedance. $i_{g a}, i_{g b}$ and $i_{g c}$ were three phase current instantaneous value of grid side inverter. $u_{g a}, u_{g b}$ and $u_{g c}$ were instantaneous voltage values of three-phase power system. $u_{c a}, u_{c b}$ and $u_{c c}$ were instantaneous output voltages of three phase inverter.

The mathematical model of the grid side inverter in the three-phase static coordinate system was transformed into the mathematical model of the dq rotating coordinate system:

$$
\left[\begin{array}{l}
u_{g d} \\
u_{g q}
\end{array}\right]=\left[\begin{array}{cc}
L \frac{d}{d t}+R & -\omega_{s} L \\
\omega_{s} L & L \frac{d}{d t}+R
\end{array}\right]\left[\begin{array}{l}
i_{g d} \\
i_{g q}
\end{array}\right]+\left[\begin{array}{l}
u_{c d} \\
u_{c q}
\end{array}\right]
$$

where $u_{g d}$ and $u_{g q}$ were components of network side voltage on dq axis. $i_{g d}$ and $i_{g q}$ components of the network side current on the dq axis. $\omega_{s}$ was voltage angle frequency. $U_{c d}$ and $U_{c q}$ were the output voltages of the inverter in the dq axis.

\section{Research on Control Strategy of Direct Drive Permanent Magnet Wind Power Generator}

\subsection{Machine Side Converter Control Strategy}

The control of direct drive permanent magnet generator mainly adopted the electromagnetic torque control motors to control the generator power or speed, to run on the optimal power curve, the maximum wind energy tracking. In this artical, the rotor field oriented vector control was used for the machine side converter. It used the rotor field oriented vector control which was based on rotor field oriented vector control on the rotating center two dimensional coordinate system. And the equivalent control of permanent magnet synchronous motor was a DC motor control. The control quantity was transformed from the rotating coordinate system to the corresponding control quantity in the three-phase static coordinate system through the coordinate transformation. The machine side converter was adopted to achieve the maximum power of wind turbine according to the maximum power tracking control. The optimal power value was obtained by the tracking curve, and then the reference value of the stator side current q axis was obtained by the formula transformation.

From the last section, we can know that the dq axis voltage equation of PMSM was: 


$$
\left\{\begin{array}{l}
U_{s d}=-R_{s} i_{s d}+\omega_{e} L_{s d} i_{s d}-L_{s d} \frac{d i_{s d}}{d t} \\
U_{s q}=-R_{s} i_{s q}-\omega_{e} L_{s q} i_{s q}-L_{s q} \frac{d i_{s q}}{d t}+\omega_{e} \psi_{f}
\end{array}\right.
$$

Permanent magnet synchronous motor electromagnetic torque control equation:

$$
T_{e}=\frac{3}{2} N_{p}\left[\psi_{f}+\left(L_{s d}-L_{s q}\right) i_{s d}\right] i_{s q}
$$

The active power of the generator was:

$$
P_{s}=T_{e} \omega_{r}
$$

where $\omega_{r}$ was Rotor speed of generator.

The following Fig. 2 represents the condition of grid voltage stability and was double closed loop control block diagram where the direct drive permanent magnet wind turbine generator side converter was based on the traditional rotor flux orientation. $Q$ outer ring was power control loop.

$Q$ control diagram of traditional shaft generator rotor flux orientation based on the traditional external loop power control loop. The output power of the generator was calculated, and the formula (11), (12) can be used to calculate the value of the $q$ axis current by tracking the maximum power curve, according to the wind turbine speed and pitch current.

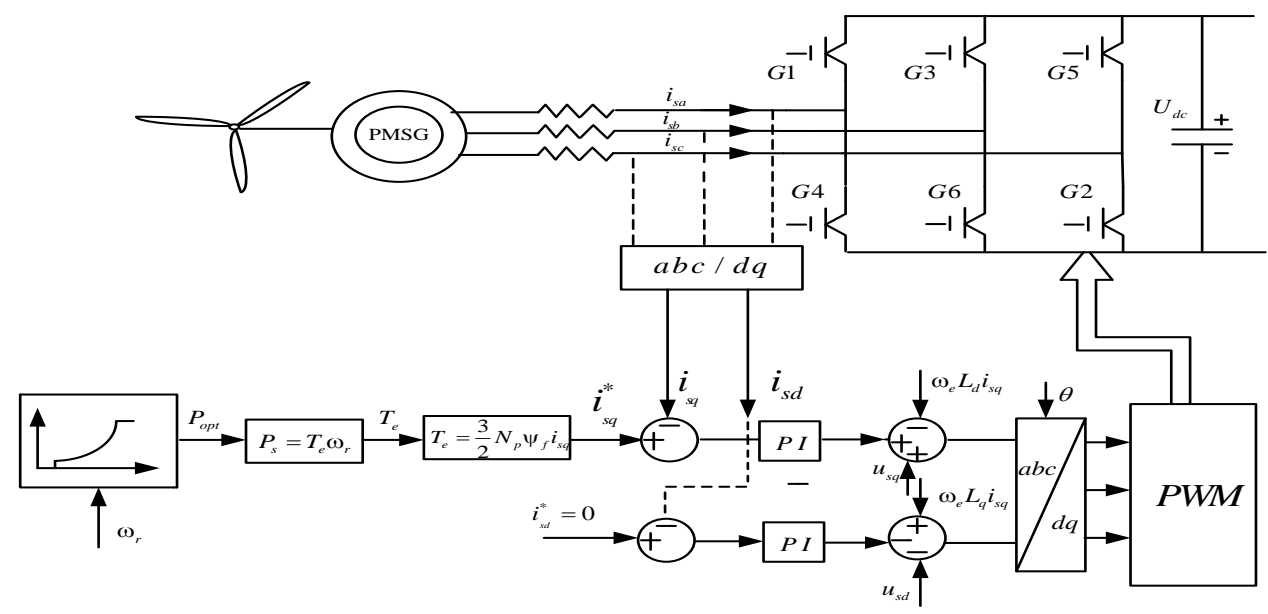

Fig. 2. The diagram of traditional machine side converter control strategy.

\subsection{Network Side Converter Control}

The main function of the grid side converter was to convert the DC inverter of the converter to AC power to the grid. Therefore, On the one hand, a network side converter have to maintain the stability of DC bus capacitor voltage, on the other hand, to ensure that the power grid to send good quality. The frequency and amplitude of the grid side converter was delivered to the grid with the same frequency and amplitude alternating current power grid. The magnitude of the active power and reactive power can be changed by adjusting the amplitude and phase of the connected grid voltage. The vector control strategy of grid voltage was utilized to grid side converter.

Network measurement converter output Pg and reactive power Qg can be illustrated with the following equations: 


$$
\left\{\begin{array}{l}
P_{g}=u_{g d} i_{g d}+u_{g q} i_{g q} \\
Q_{q}=u_{g d} i_{g q}-u_{g q} i_{g d}
\end{array}\right.
$$

Because the voltage directional vector control was adopted, the $d$ axis of the rotating coordinate system was fixed on the voltage vector of the network:

$$
\left\{\begin{array}{l}
u_{g d}=e \\
u_{g q}=0
\end{array}\right.
$$

So on type (13) can be written as:

$$
\left\{\begin{array}{l}
P_{g}=e_{d} i_{g d} \\
Q_{g}=-e_{d} i_{g q}
\end{array}\right.
$$

where $e_{d}$ was grid voltage vector. $i_{g d}$ was Network side active current component. $i_{g q}$ was reactive current component for the network side.Decoupling control of active power and reactive power can be achieved by controlling the active and reactive current.

The feed forward compensation strategy was adopted, and the current inner loop was controlled by PI:

$$
\left\{\begin{array}{l}
u_{g d}=-\left(K_{p}+\frac{K_{i}}{s}\right)\left(i_{g d}^{*}-i_{g d}\right)+\omega_{s} L_{g} i_{g q}+e_{d} \\
u_{g q}=-\left(K_{p}+\frac{K_{i}}{s}\right)\left(i_{g q}^{*}-i_{g q}\right)+\omega_{s} L_{g} i_{g d}+e_{q}
\end{array}\right.
$$

where $K_{p}$ were $K_{i}$ were proportional coefficient and integral coefficient of PI regulator. $e_{d}$ and $e_{q}$ were $\mathrm{dq}$ axis components for grid voltage.We know that the outer loop voltage loop and its main function was to stabilize the DC bus voltage, so its control was $U_{d c}^{*}$ given the measured DC bus voltage and $U_{d c}$ bus voltage value, the difference between the PI regulator output as $i_{d}^{*}$ which was grid side active current reference value.

The specific control block diagram of the network side voltage outer loop was shown below.

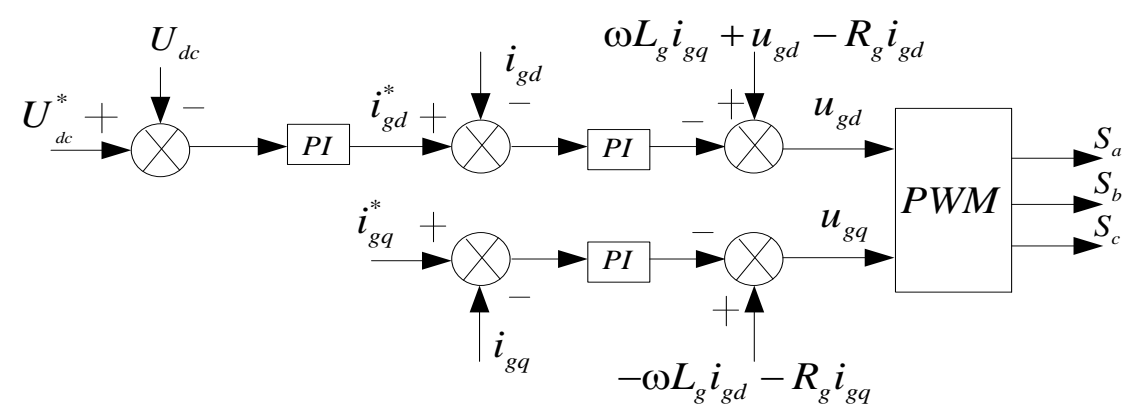

Fig. 3. The diagram of the network side converter circuit.

\section{Improved Low Voltage Ride through Control Strategy}

The torque of permanent magnet synchronous motor (PMSM) was composed of two parts, the 
electromagnetic torque and the reluctance torque, and the reluctance torque was composed of dq axis current. The electromagnetic torque was a linear function of the $\mathrm{q}$ axis current. When the control way that was $i_{d}=0$ was been used, the result was equivalent to neglecting the reluctant $i_{d}$ of $\mathrm{d}$ axis can be compensated. The d axis current to produce magnetic effects, weakening the rotor flux, increasing reluctance torque, dq axis current with each other, the back EMF was reduced and the output power was reduced, maintenance of DC capacitor power balance was low voltage ride through unit safety.

The electromagnetic torque equation of permanent magnet synchronous motor was presented in the second chapter:

$$
T_{e}=\frac{3}{2} N_{p}\left[\psi_{f}+\left(L_{s d}-L_{s q}\right) i_{s d}\right] i_{s q}
$$

In the steady operation of the power grid voltage, using the mode that was $i_{d}=0$ to control, the electromagnetic torque expression can be written as:

$$
T_{e}=\frac{3}{2} N_{p} \psi_{f} i_{s q}
$$

If there was negative compensation for the $d$ axis current during the low voltage:

$$
T_{e}=\frac{3}{2} N_{p}\left[\psi_{f}-\Delta \psi_{f}\right] i_{s q}
$$

Among them, $\Delta \psi_{f}=\left(L_{s d}-L_{s q}\right) i_{s d}$.So during LVRT, electromagnetic torque, reluctance torque increases, the generator output active power will be reduced. The DC bus voltage to determine the size of the size of the $d$ axis compensation current, when the DC bus voltage was greater, indicating the storage of the DC bus energy more $d$ axis compensation current was greater. So $\mathrm{D}$ axial compensation current reference value can be expressed as:

$$
i_{s d}^{*}=K_{d}\left(1+\frac{1}{s T_{d c}}\right)\left(u_{d c}^{*}-u_{d c}\right)
$$

where $K_{d}$ and $T_{d c}$ were the proportional coefficient and integral coefficient of $\mathrm{d}$ axis current compensation. The improved permanent magnet direct drive low voltage ride through machine side control block diagram was shown as follows.

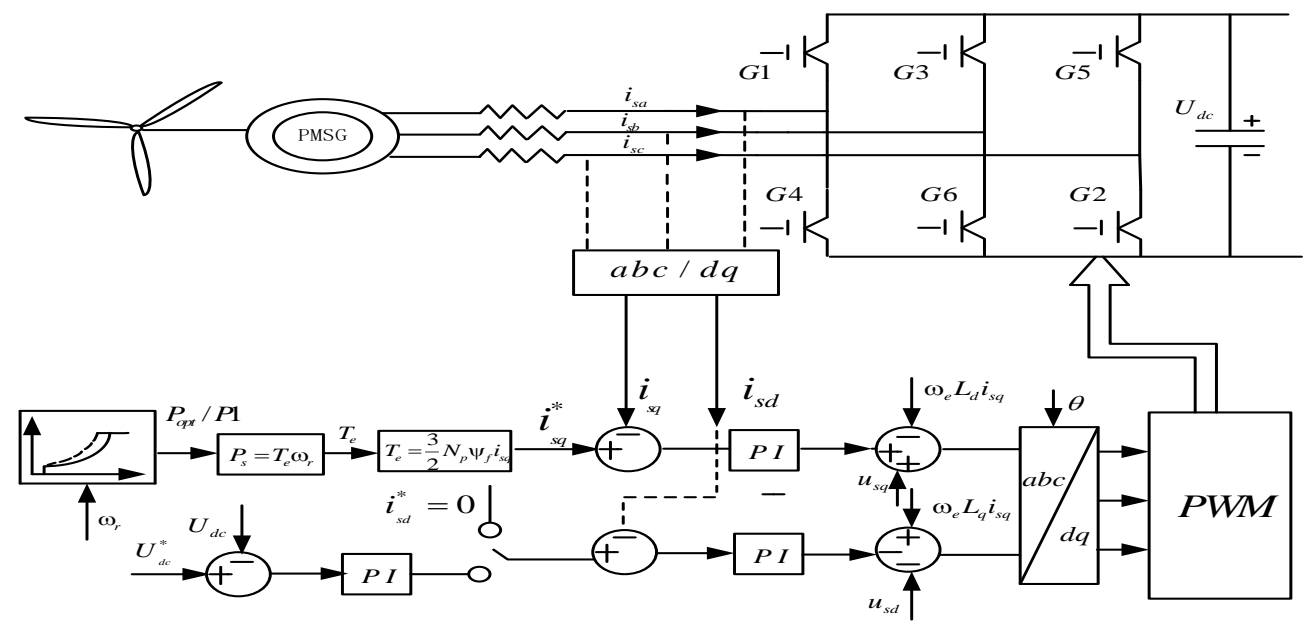

Fig. 4. The control block diagram of improved machine side converter. 


\section{Simulation Analysis}

\subsection{Simulation Example 1}

When the outside wind speed was $12 \mathrm{~m} / \mathrm{s}$, the running characteristics of the direct drive permanent magnet wind turbine were analyzed by simulation. Due to the inertia of the unit, the starting speed was slow, and the simulation time was 30 s.

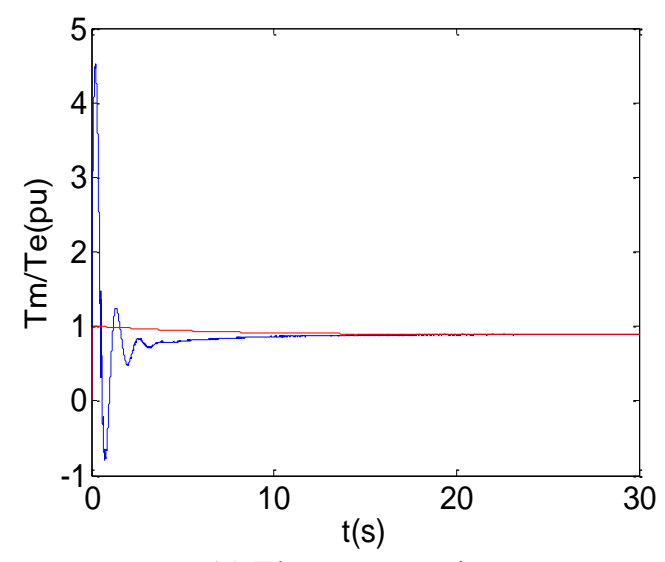

(a) Electromagnetic torque

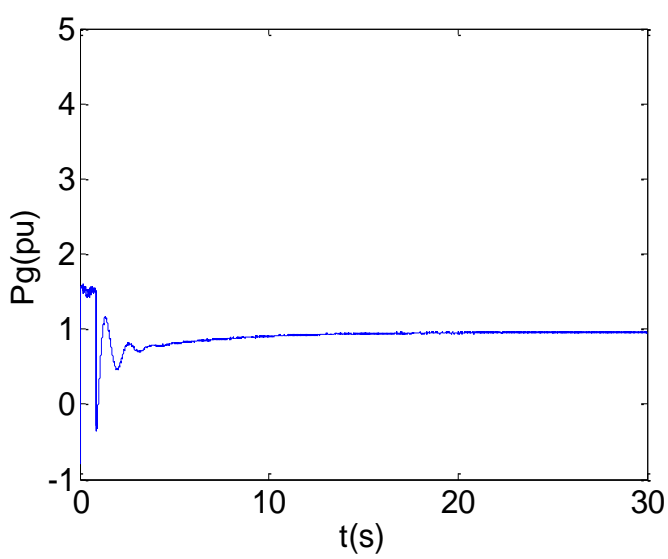

(c) Net output active power

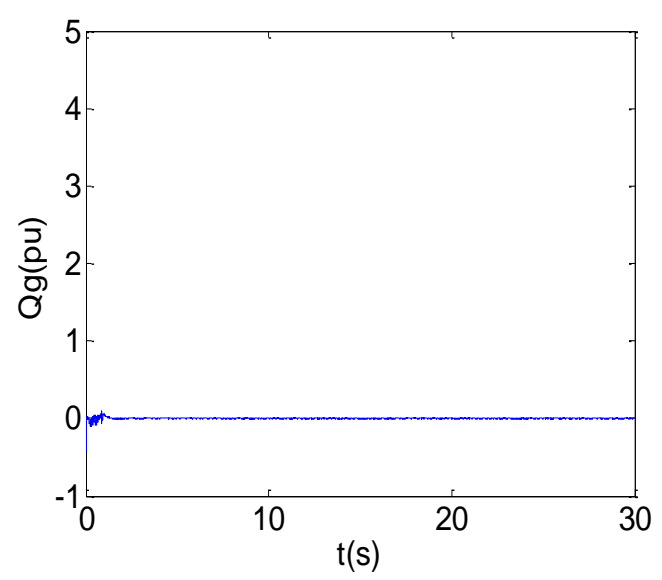

(e) Net output reactive power

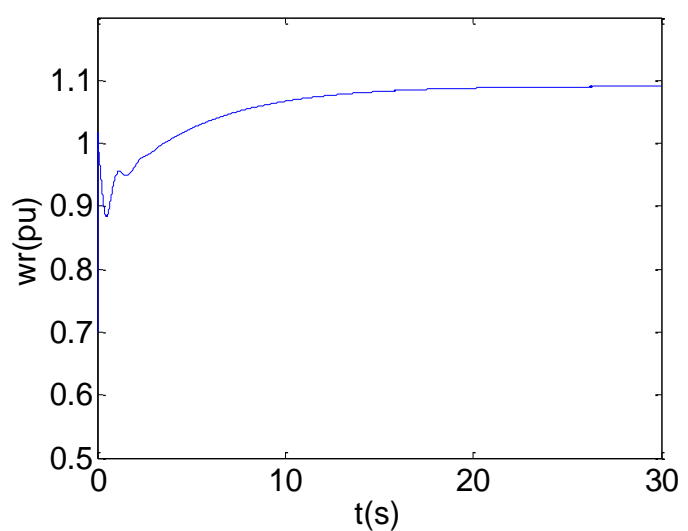

(b) Rotor speed

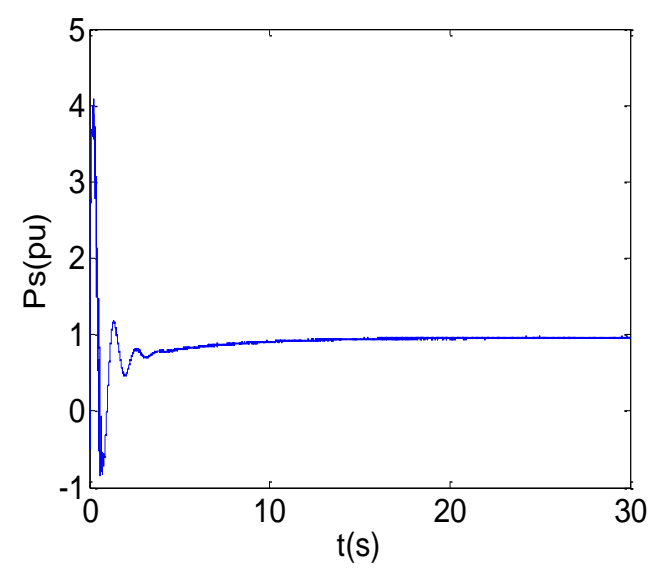

(d) Output active power

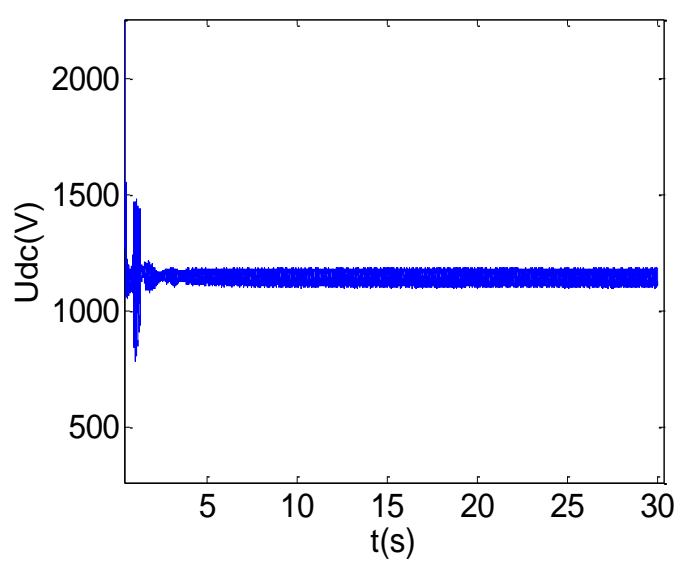

(f) DC capacitor voltage

Fig. 5. The simulation waveform diagrams of the normal operation of D-PMSG.

When the direct drive permanent magnet wind turbine was in steady state, the rotor side was based on the rotor flux oriented vector control strategy. Diagram 5(a) was the mechanical torque and torque waveform output of wind turbine, 5(b) was a permanent magnet synchronous motor speed waveform. At 
the beginning of the system, the unit had large inertia, the starting speed was slower, the mechanical torque of the permanent magnet synchronous motor was greater than the electromagnetic torque, so the speed of the generator increased gradually. After the operation of 10s, the electromagnetic torque of the generator was close to the mechanical torque, and the rotor speed tended to be stable gradually. Diagram 5(c) was the active power output the generator's, and 5(d) was the active power into the grid. In steady-state operation, the active power which was output of the machine side was equal with one into the network side. Diagram 5(e) was almost equal to the reactive power network side output, and reactive power was 0 in the steady operation. Diagram 5(f) was the waveform of DC capacitor voltage, the rated value was $1150 \mathrm{~V}$. The above waveform reflected the steady state characteristic of direct drive wind turbine, and verified the correctness of the simulation model.

\subsection{Simulation Example 2}

When the wind velocity was $12 \mathrm{~m} / \mathrm{s}$, the grid voltage started to drop symmetrically at 20 s and ended after $0.625 \mathrm{~s}$, fell by $50 \%$. The simulation was divided into two steps. Firstly, to reduce generator output by the maximum power curve, and switch with pitch angle and crowbar circuit coordination control. Series of as shown in the waveform could be achieved by simulation analysis (blue curve). Then simulation and analysis were carried out with the improved low voltage ride through control strategy, the following specific simulation results were shown on the right (red curve).

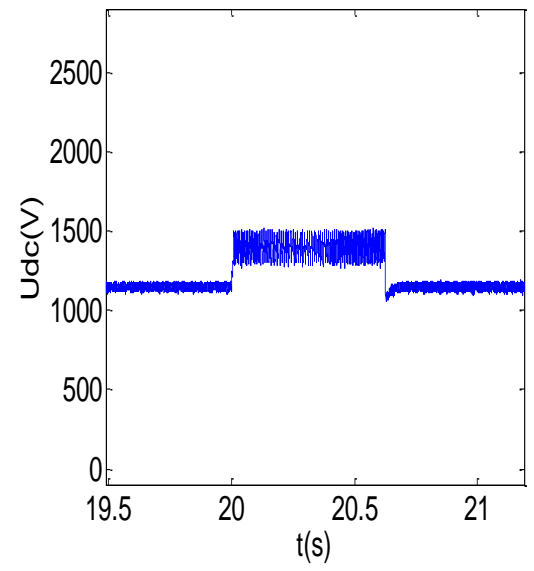

(a) Improved DC capacitor voltage

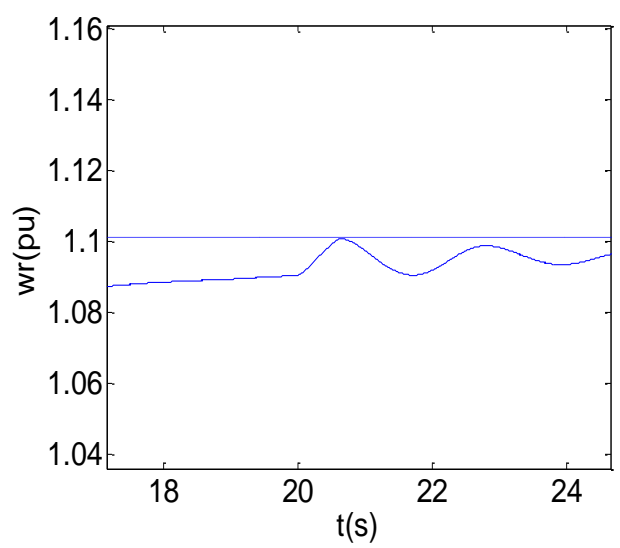

(c) Rotor speed improvement

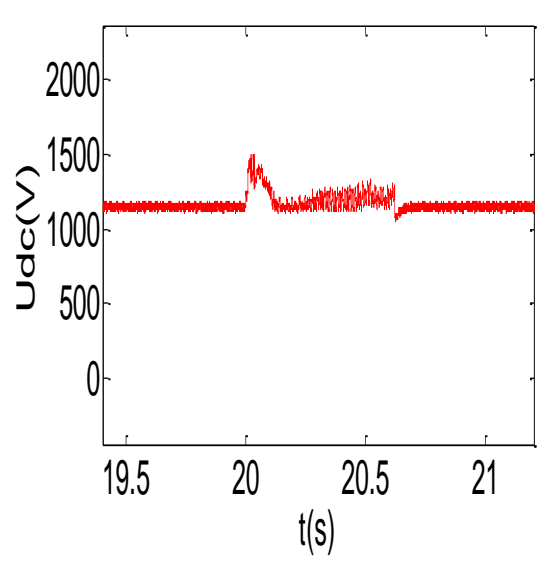

(b) Improved DC capacitor voltage

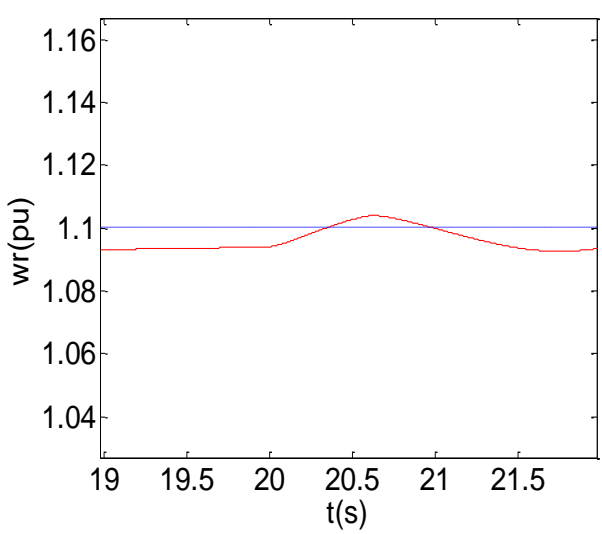

(d) Improved rotor speed

Fig. 6. Comparison of the simulation waveform figures which direct-drive wind turbines with low voltage passes through before and after the improvement.

Diagram 6(a) was DC bus voltage waveform by traditional strategy. The DC bus voltage waveform was 
improved in diagram 6(b). After the contrast analysis showed that, the DC bus voltage in (a) was significantly greater than (b), and the turn-on threshold the Crowbar circuit was triggered. The DC bus voltage in (b) rose at the beginning, then it tended to be stable. so the rise of the DC bus voltage was well restrained, the DC unloading resistance was reduced. Diagram 6(c) and (d) reflected the rotor speed waveform before and after the improvement. During the grid voltage sags, rotor speed rise, the change of speed was not very obvious as the unit of inertia. The unbalanced power of DC bus storage was more, mechanical inertia energy storage was less, the rotor speed changed in a small way and pitch had no action,DC bus storage unbalanced power more mechanical inertia energy storage was less, the rotor speed changes smaller pitch control improvements without action. More unbalanced energy of DC capacitor was converted into kinetic energy after the improvement strategy, and the rotor speed exceeded the rated value of 1.1pu. Low voltage rode through the unit safely by starting the pitch control, beginning to collect the oars and reducing wind energy capture with the machine.

\section{Conclusion}

In this study, it is found that LVRT capability of DPMSG will be greatly affected, when the DC bus has unbalanced storage, more power, less mechanical inertia energy, little change in rotor speed and no angle of pitch. Therefore, it is very important to reduce the wind energy capture and match the generator side converter to reduce the generator output.This paper presents a novel flux-weakening control method, HFWC ,for stability control of direct driven wind turbine. The method utilizes the DQ axis current cooperate with each other during the grid voltage sags. Compared with the traditional method, it further reduces the generator output, makes full use of the mechanical inertia energy storage, reactive power compensation, and reduces the use of the frequency of unloading resistance, can make the wind turbine safe low voltage ride through. So the validity of this scheme is be proved.

\section{References}

[1] Zheng, R. M. (2013). There search on technologies of low voltage ride through for direct-driven permanent magnet wind power system. North China Electric Power University.

[2] Zhang, J. D. (2014). The power control and the simulation research on the termanent magnet direct drive wind turbine.

[3] Meng, Y. Q., Wang, J., Li, L., \& Wang, X. L. (2015). New low voltage ride-through coordinated control schemes of permanent magnet synchronous generator considering rotor speed limit and DC dwascharging circuit optimization. Proceedings of the Chinese Society for Electrical Engineering, 35(24), 3-4.

[4] Li, Y. (2012). Research on converter technology and low voltage ride through for direct-drive wind power system[D]. North China Electric Power University.

[5] Chen, H. (2013). The study of LVRT capability simulation of direct-driven permannent magnet wind power generator unit [D]. Northeast Electric Power University.

[6] Wu, Z. Q., Yang, Y., \& Xu, C. H. (2015). Adaptive fault diagnosis and active tolerant control for wind energy conversion system. International Journal of Control, Automation and Systems, 13(1), 120-125.

[7] Yousef, A., Nasiri, A., \& Abdelbaqi, 0. (2014). Wind turbine level energy storage for voltage ride through (LVRT) support. Power Electronics and Machines for Wind and Water Applications (PEMWA), 11(6), 2-6.

[8] Alepuz, S., Alejandro, C., Monger, S. B., et al. (2013). Use of stored energy in PMSG rotor inertia for low-voltage ride-through in back-to-back NPC converter-based wind power systems. IEEE Transactions on Industrial Electronics, 60(5), 7-9.

[9] Zhu, X., Chao, Q., Yuan, T. J., et al. (2014). Low voltage direct drive permanent magnet wind power 
system operation and control of super capacitor energy storage. Acta Energiae Solaris Sinica, 35(8), 2-3. [10] Yao, J., Chen, X. Y., Xia, X. F., et al. (2012). A low voltage ride-through control strategy for direct-driven permanent magnet wind power generation system with flywheel energy storage unit. Automation of Elec-tric Power System, 36(13), 7-14.

[11] Li, H. M., Zhang, X. Y., Wang, Y., et al. (2012). Virtual inertia control of DFIG-based wind turbines based on the optimal power tracking. Proceedings of the Chinese Society for Electrical Engineering, Vol. 32, No. 7 (pp. 4-5).

[12] Gilmanur, R., \& Mohd, H. (2017). Fault ride through capability improvement of DFIG based wind farm by fuzzy logic controlled parallel resonance fault current limiter. Electical Power Systems Research, 146(1), 1-8.

[13] Gao, J. (2013). Research on Design Technology and Application of Direct-Drive Permanent Magnet Generator with Wind Turbine. Hunan University.

[14] Zhao, M. H. (2016). Research on Flux-Weakening Control Technology of Permanent Magnet Synchronous Motor. Shenyang University of Technology.

[15] Zhang, C. Y., Feng, X. Y., Xu, J. F., et al. (2014). Research on the control strategy of IPMSM for the flux weakening operation. Electric Drive, 44(5), 2-4.

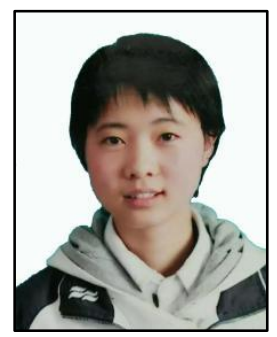

Huiting Chen was born in Jiangsu, China, in 1993. She is currently pursuing her M.S. degree at Shanghai Dianji University, Shanghai, China. Her interasts include wind power generation, wind power converter, and power quality management.

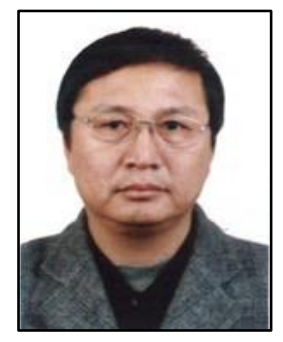

Shaojie Xin was born in Shandong, China, in 1963. He received his Ph.D degree at mechanical design and theory from Harbin Institute of Technology, China, in 2002. He was appointed the professor of mechanical engineering at Shanghai Dianji University, in 2003. His research interests include mechanics theory and application, robot technology and application, mechanical equipment fault diagnosis technology.

Over the years, as the main member, he participated in a key project of National Natural Science Fund Project and a national 863 project, two national torch plan and a science and technology enterprise innovation fund project. As the host, he took China National Petroleum Company EOR guide to technical research projects, the Shanghai Municipal Science and technology project, Daqing Petroleum Administration and the Daqing Municipal Bureau and Minhang District science and technology project and enterprise commissioned project.

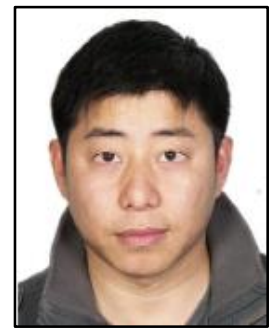

Enxing Yang was born in 1977. He received his Ph.D degree at power electrics and power transmission from Zhejiang University, China, in 2009. His interests include wind power converter, and power quality management. As the main member, he participated in A number of large-scale wind power projects. 